\title{
Understanding Life in Academia: A Guide for Inspired Undergraduates
}

\author{
Christopher R. Madan \\ Department of Psychology, University of Alberta
}

So you just got involved in a research lab and are starting to hear a lot of new vocabulary like "tenure," "postdoc," and "NSERC". You may ask your new colleagues what some of these terms mean, but you might also feel embarrassed having no idea about so many of these new terms. Instead of nodding along in bewilderment, let's go through a quick primer on life in academia and the major Canadian funding agencies. If you haven't become involved in a research, please see our earlier guide to get you started! (Madan \& Chen, 2012, Eureka, "Getting involved in research: A guide for inspired undergraduates")

\section{POSITIONS WITHIN THE LABORATORY ENVIRONMENT}

First, let's start from where you are currently, an undergraduate research assistant. The position of research assistant is often abbreviated as RA. To have a position like this, you likely are volunteering, doing a 400-level research course, or have your own Honors project. Research assistants usually help with data collection, attend lab meetings, and read research papers. Depending on the field, other responsibilities may also exist. Honors students are often required to complete a thesis paper at the end of their degree, describing the background, methods, and results of their study. Some labs also have lab managers, who help with overseeing the day-to-day function of the lab, including administrative responsibilities. Lab manager is usually a full-time position and requires the completion of a bachelors degree.

The next step up is graduate students. Graduate students have completed a Bachelor's degree (BSc or BA), and are now either Masters (MSc [science] or MA [arts]) or PhD (Doctor of Philosophy) students. Students at either level can be referred to as graduate student or 'grad student', but referring to them as a Masters or PhD student would be more precise. PhD students can be further subdivided based on if they have completed an important exam called the candidacy, which usually involves an oral examination designed to test that they have sufficient background knowledge for their dissertation research. A dissertation usually consists of a number of research studies and serves as the main requirement of the $\mathrm{PhD}$ degree. It's quite similar to an Honors student's thesis, but larger in scope. After completing this candidacy exam, the student can then refer to themselves as a PhD candidate. After a PhD candidate completes their $\mathrm{PhD}$, it is time to move on. Many possibilities are open to this newly minted PhD graduate. Within the realms of academia, the two most likely subsequent positions are postdoctoral research fellow and sessional lecturer. After completing either a Masters or $\mathrm{PhD}$, it is also common to transition to an industry position. Industry positions may be tailored to the individual's specialty, such as pharmaceuticals, marketing, or software development, or may be broader such as scientific journalism.

A postdoctoral research fellow (postdoc or PDF) works with another professor, more as an equal, to exchange techniques and learn to supervise their own laboratory. This position usually is held for 2-3 years before the postdoc applies for a tenure-track professor, sessional lecturer, faculty lecturer, or industry position. An alternative path is to become a sessional lecturer, which is entirely a teaching position, with little or no required research component. Sessional lecturers are hired at universities entirely on a contractual basis. Faculty lecturers are permanent lecturing positions (i.e., long-term contracts).

At the level of professor, there are also a few subtle distinctions in position. In Canada, when a professor first begins, they are an assistant professor. After a few years, approximately six, the professor applies for tenure, which essentially guarantees the professor a position at the university until retirement. The review process for becoming tenured requires the professor to demonstrate that they have a strong academic record (i.e., publishing papers, supervising students), funding (described in detail later), and teaching. After obtaining tenure, the professor's rank moves up to associate professor. When the professor becomes more senior, they become a full professor, or simply professor. Becoming a full professor is never a gauranteed promotion by seniority, it is a very esteemed position that requires a substantial cumulative research record. At all of these levels, by supervising a research lab, the professor is also a principle investigator or PI.

Note, someone that teaches a class is not necessarily a professor. For instance, sessional and faculty lecturers often teach, as can PhD candidates. The correct position for someone teaching a class is instructor. Nearly all instructors have received their $\mathrm{PhD}$, and thus should be referred to as "Dr.", though this is not in the same sense as a MD (Doctor of Medicine).

Every so often, usually every seventh year, a professor can take a year off, referred to as a sabbatical. During this year the professor often works to catch-up on previous projects (i.e., write papers) or visit researchers at other universities to develop collaborations and learn new techniques. This is a paid leave of absence from the university.

After a professor has retired, if they still continue to be 
involved in research and affiliated with the university, they may be given the title professor emeritus.

\section{FUNDING AGENCIES}

In Canada, money that funds research comes from funding agencies. Most of these agencies are part of the federal or provincial government, but some may be associated with non-profit organizations. These are the funds that are used to pay for ongoing expenses such as chemical reagents or paid participants, as well as buy new equipment, support staff such as lab managers, cover conference travel and training courses, and sometimes pay for graduate stipends.

In Canada, three funding agencies exist as part of the federal government, together are referred to as the tri-council. The agency most relevant to basic science and engineering research is NSERC, the Natural Sciences and Engineering Research Council (http: // www.nserc-crsng.gc.ca). Health-related research is funded by CIHR, the Canadian Institutes of Health Research (http://www.cihr-irsc.gc.ca). The last agency is the Social Sciences and Humanities Research Council or SSHRC (http://www.sshrc-crsh.gc. $\mathrm{ca}$ ). Professors often apply to one or more of these agencies to obtain research grants to fund their research and graduate students apply to these agencies for scholarships. While these are the main federal agencies, others exist, such as the Canadian Foundation for Innovation (CFI; http: / / www. innovation.ca).

At the provincial level is Alberta Innovates (http: //www.albertainnovates.ca). Of the agencies that comprise Alberta Innovates, two are particularly relevant: Alberta Innovates Technology Futures (AITF; http: / / www . albertatechfutures.ca) has a similar scope to NSERC. This agency was formerly known as Alberta Ingenuity. Alberta Innovates Health Solutions (AIHS; http: / / www. aihealthsolutions.ca) has a similar scope to CIHR and is formerly known as AHFMR (Alberta Heritage Foundation for Medical Research). Again, while these are the most broadly relevant provincial agencies, several others exist. Two of these include the Alberta Gambling Research Institute (AGRI; http://www.abgamblinginstitute. ualberta.ca) and Alberta Centre for Child, Family \& Community Research (ACCFR; http://www . research 4 children.com).

Of these agencies, two offer undergraduate research scholarships that can pay for you to do research over the summer: NSERC USRA (Undergraduate Student Research Award; http://www.nserc-crsng.gc. $\mathrm{ca} /$ students-etudiants/ug-pc/usra-brpc_

eng.asp) and AIHS Summer Studentships (http://www.aihealthsolutions.ca/funding/ training-and-early-career-funding/ undergraduate-high-school/ summer-studentships/).

\section{CONCLUSION}

Hopefully this brief primer was able to orient you to your new research environment. If you hear any additional terms that were not covered here, ask your colleagues. They likely will be happy to satiate your interest in research!

FUN FACTS: PhD stands for Doctor of Philosophy, regardless of what field the student actually researches. In Germany, an RA is referred to as a HIWI (short for "Hilfswissenschaftler," which literally translates to "assistant scientist"). 